\title{
ИЗУЧЕНИЕ КИНЕТИКИ ГИБЕЛИ СПОР CLOSTRIDIUM BOTULINUM ВО ФРУКТОВЫХ КОНСЕРВАХ
}

\author{
Р.А. Волкова, Т.А. Позднякова, М.Т. Левшенко
}

\begin{abstract}
В Российской Федерации считается, если величина $\mathrm{pH}$ консервов из персиков, абрикосов и груш превышает 3,8, в них возможно развитие и токсинообразование Clostridium botulinum, поэтому они выделены в отдельную группу. Недавними исследованиями установлено, что существующее выделение консервов из персиков, абрикосов и груш в особую группу, необходимо пересмотреть, так как споры C. botulinum в этих консервах с pH ниже 4,5 не развиваются, а гибнут с различной скоростью, в зависимости от величины рН консервов.

В представленной работе продолжено изучение кинетики гибели спор C. botulinum во фрруктовых консервах из тропических фрруктов манго и бананов с рH от 3,8 до 4,5. Экспериментально установлена кинетика гибели спор C. botulinum при хранении консервов из манго и бананов в течение 24 месяцев. К концу двухгодичного срока хранения в продукте с $\mathrm{pH}$ 3,9 и 4,2 остались жизнеспособными лишь единичные споры в см³ продукта, а в продукте с pH 4,5 выжили десятки спор в см ${ }^{3}$ продукта. Кинетика гибели спор C. botulinum в манговом и банановом пюре аналогична скорости гибели спор в абрикосовом пюре при равных значениях рН продукта.
\end{abstract}

Таким образом, проведенные исследования подтверждают предложение изменить подходы к делению фрруктовых консервов на группы и соответственно, к разработке режимов стерилизации (пастеризации) консервов из абрикосов, персиков и груш.

Ключевые слова: Clostridium botulinum, консервы из абрикосов, манго и бананов, выживаемость бактериальных спор, $\mathrm{pH}$ консервов, деление консервов на группы.

\section{ВВЕДЕНИЕ}

Одной из важнейших отраслей пищевой промышленности является производство фрруктовых консервов для детского питания. Манго и бананы широко используются при производстве пюреобразных консервов для детского питания.

В Российской Федерации консервы, в зависимости от их активной кислотности $(\mathrm{pH})$ продукта, делятся на группы А, Б, В и Г [1]. Деление консервов на эти группы связано с возможностью развития в них $C$. botulinum. В Российской Федерации считается, что в консервах групп А и Б с рН более 4,2 и неконцентрированных томатных продуктах развитие $C$. botulinum возможно, в концентрированных томатных продуктах и консервах группы В с величиной $\mathrm{pH} 3,7-$ 4,2 - маловероятно, в консервах группы Г с рН менее 3,7 - невозможно [2,3].

В работах [4] и [5], проведенных в 60-70 годах XX века, показана возможность развития и токсинообразования $C$. botulinum в консервах из абрикосов с рН ниже 4,0. Однако данные исследования не бесспорны. На основании этих экспериментов, вся нормативная документация по контролю производства фрруктовых консервов из абрикосов, персиков и груш, в части определения соответствия консервов требованиям промышленной стерильности, основана на том, что данные виды консервов, как исключение, включены в группу А [1]. Следовательно, при выработке этих консервов с рН выше 3,8 их стерилизуют при температуре порядка $110{ }^{\circ} \mathrm{C}$ в течение времени, обеспечивающего гибель спор C. botulinum.

Недавними исследованиями [6] установлено, что существующее выделение консервов из персиков, абрикосов и груш в группу А, необходимо пересмотреть, так как споры $C$. botulinum в этих консервах с $\mathrm{pH}$ ниже 4,5 не развиваются, а гибнут с различной скоростью, в зависимости от величины $\mathrm{pH}$ консервов.

Для расширения ассортимента ранее исследованных фрруктовых консервов [6], по изучению кинетики гибели спор, нами были изучены пюре из манго и бананов.

Цель исследования: изучить кинетику гибели спор C. botulinum в продуктах из манго и бананов $\mathrm{c} \mathrm{pH}$ ниже 4,5. Это необходимо для разработки научно обоснованных режимов стерилизации и пастеризации фруктовой консервированной продукции, обеспечивающих ее качество и безопасность. 


\section{ИЗУЧЕНИЕ КИНЕТИКИ ГИБЕЛИ СПОР CLOSTRIDIUM BOTULINUM ВО ФРУКТОВЫХ КОНСЕРВАХ}

Задача исследования: проведение на современном уровне репрезентативного комплекса экспериментов для изучения кинетики гибели спор $C$. botulinum в однокомпонентных консервах из манго и бананов с рH ниже 4,5. Доказательство гибели спор $C$. botulinum в данных консервах с рН ниже 4,5 станет дополнительной базой для того, что бы отнести консервы из абрикосов, персиков и груш к группе Г, вместо существующего, в виде исключения, к группе А. Консервы из фрруктового сырья имеют гарантированный срок годности 1-2 года. Исходя из этого, актуальным является исследование кинетики гибели спор C. botulinum в течение данного срока годности консервов.

\section{МАТЕРИАЛЫ И МЕТОДЫ ИССЛЕДОВАНИЯ}

Использованные методы описаны в статье [6]. Исследования проводили с использованием музейных культур микроорганизмов, имеющихся в лаборатории качества и безопасности пищевой продукции ВНИИТеК. В работе использовали споры C. botulinum типа В (штамм B-364). Этот тип является наиболее частым возбудителем пищевых отравлений ботулинической этиологии от плодоовощных консервов. Вторым штаммом был взят C. botulinum типа А (штамм A-98), как наиболее кислотоустойчивый тип [3].

Споровые суспензии C. botulinum для заражения консервов получали в соответствии с «Положением о разработке режимов стерилизации и пастеризации консервов... » [7] на жидкой питательной среде, содержащей гидролизат казеина - «Soyabean Casein Digest Medium - Tryptone Soya Broth» («HiMedia», Индия). На этой среде были получены суспензии, содержащие не менее 70 \% спор.

Титр полученных споровых суспензий определяли методом десятикратных разведений с посевом по $1 \mathrm{~cm}^{3}$ каждого из приготовленных разведений на плотную питательную среду в трубки Вейона с последующим прямым подсчетом числа выросших колоний. С целью повышения статистической надежности результатов подсчета, посев проводили в две параллельные трубки Вейона на одно разведение. Полученные суспензии содержали не менее $1,0 \times 10^{7}$ спор в $1 \mathrm{~cm}^{3}$.

Подсчет количества выросших колоний проводили способом прямого учета их числа по ГОСТ ISO 7218-2015 [8]. При этом рассчитывали число спор, присутствующих в пробе, как средневзвешенное значение из двух подсчетов последовательных разведений по фрормуле:

$$
\mathrm{N}=\sum \mathrm{c} /(\mathrm{V} \times 1,1 \times \mathrm{d}),
$$

где: $\mathrm{N}$ - количество спор, $\Sigma$ с - сумма колоний, подсчитанных в двух параллельных трубках Вейона, выбранных для подсчета из двух последовательных разведений, V объем посевного материала, внесенного в каждую трубку Вейона (см³), d - коэфффициент разведения, соответствующий первому выбранному разведению (в случае отсутствия разведения - $d=1)$. Результат вычисления округляли до двух значащих цифр.

Образцы фруктовых консервов для заражения спорами вырабатывали в соответствии с Технологической инструкцией (ТИ) по производству фруктовых пюреобразных консервов для детского питания [9].

Для доведения $\mathrm{pH}$ продукта, до требуемой величины в консервах, использовался способ прямого подкисления или подщелачивания приготовленных пюре [10]. Натуральное пюре из манго имело низкое значение величины $\mathrm{pH}$ около 3,7 поэтому, чтобы получить продукт с рН 3,8 и 4,0, пюре подщелачивали. Пюре из бананов, имевшее начальную величину $\mathrm{pH} 4,48$, доводили подкислением до величины $\mathrm{pH} 3,9$ и 4,2.

Полученный продукт, имеющий температуру $60^{\circ} \mathrm{C}$, расфрасовывали в стеклянные бутылки вместимостью 250 см $^{3}$ с крышками «Твист-Оффф» винтового типа. Бутылки укупоривали вручную, затем стерилизовали в водяном автоклаве в соответствии с ТИ.

В простерилизованные образцы консервов вносили, открывая бутылки, с соблюдением правил асептики смесь спор C. botulinum типов А и В, в равном соотношении, в количестве около1,0×104 спор на $1 \mathrm{~cm}^{3}$ продукта. Перед внесением спор, для исключения избыточного растворения воздуха и сохранения анаэробных условий, консервы прогревали в термостате при температуре $60^{\circ} \mathrm{C}$ около 60 мин.

Консервированные продукты, заражённые смесью спор C. botulinum типов А и В, хранили в оптимальных для развития спор условиях - при температуре $30 \pm 1{ }^{\circ} \mathrm{C}$. После заражения и через каждые 3 месяца хранения консервов проводили определение количества выживших спор в продукте [11].

Определение величины $\mathrm{pH}$ проводили непосредственно в продукте потенциометрическим методом с использованием рН метра «HANNA pH 211» (Румыния). Суммарная погрешность определения $\mathrm{pH}$ этим прибором не 
более $\pm 0,05 \mathrm{pH}$ в диапазоне $2-9 \mathrm{pH}$, при температурах измеряемых образцов и окружающей среды $15-40^{\circ} \mathrm{C}[12]$.

\section{РЕЗУЛЬТАТЫ И ОБСУЖДЕНИЕ}

Недавние результаты исследований показали кинетику гибели спор C. botulinum во фрруктовых консервах из абрикосов, персиков и груш с рН ниже 4,5 в течение периода хранения [6]. Кинетика гибели спор C. botulinum в абрикосовом пюре приведена на рис. 1.

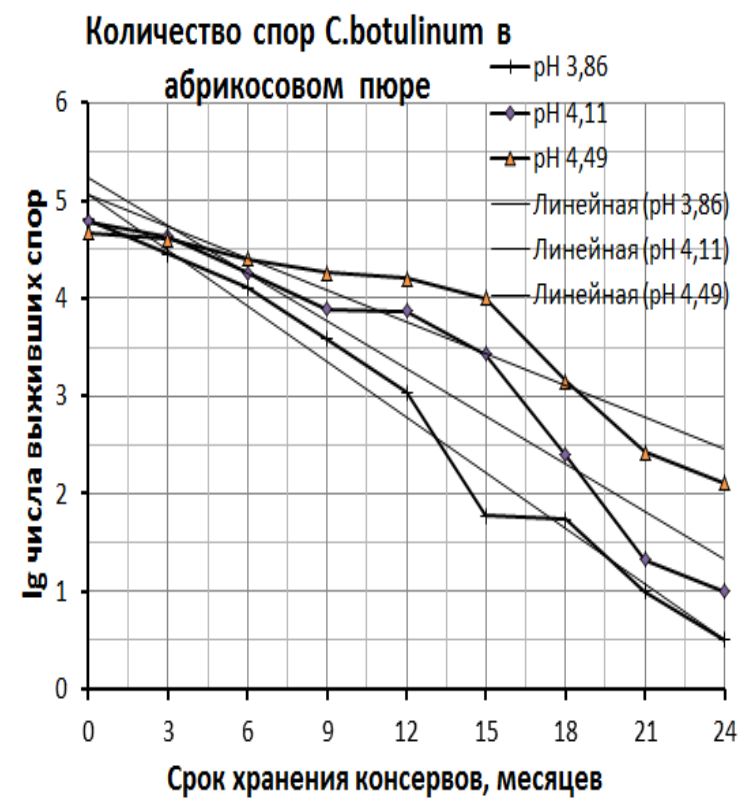

Рисунок 1 - Кинетика гибели спор C. botulinum в абрикосовом пюре при различной величине рН продукта [6]

На рисунке с помощью линий тренда наглядно отображаются тенденции изменения количества спор при различном рН продукта во время хранения.

Линия тренда - это графическое представление закономерности изменения ряда данных, вычисляемым по уравнению в программе Excel:

$$
y=a x-b
$$

Здесь: y - исследуемая переменная (log количества спор); х - число, определяющее позицию (второй, третий и т.д. месяц в период хранения), а - точка пересечения с осью у на графике (максимальный уровень); b - это значение, на которое уменьшается следующее значение временного ряда.

В абрикосовом пюре гибель спор $C$. botulinum началась после трех месяцев хране- ния в продукте с рН 3,86, с рН 4,11 - после шести месяцев хранения, а с рН 4,49 - после двенадцати месяцев. В дальнейшем гибель спор происходила быстрее в более кислых условиях при рН 3,86 и 4,1, чем при рН продукта 4,5 . Поэтому к концу двухгодичного срока хранения абрикосового пюре в продукте с $\mathrm{pH} 3,9$ и 4,1 выжили лишь единичные споры в см3 продукта, а при рН 4,5 выжили десятки спор [6].

Полученные экспериментальные данные по изучению кинетики гибели спор в пюре из манго и бананов, представлены на рисунках 2 и 3. На этих рисунках приведены так же линии тренда гибели спор для каждого значения рН продукта.

\section{Количество спор C.botulinum в банановом}

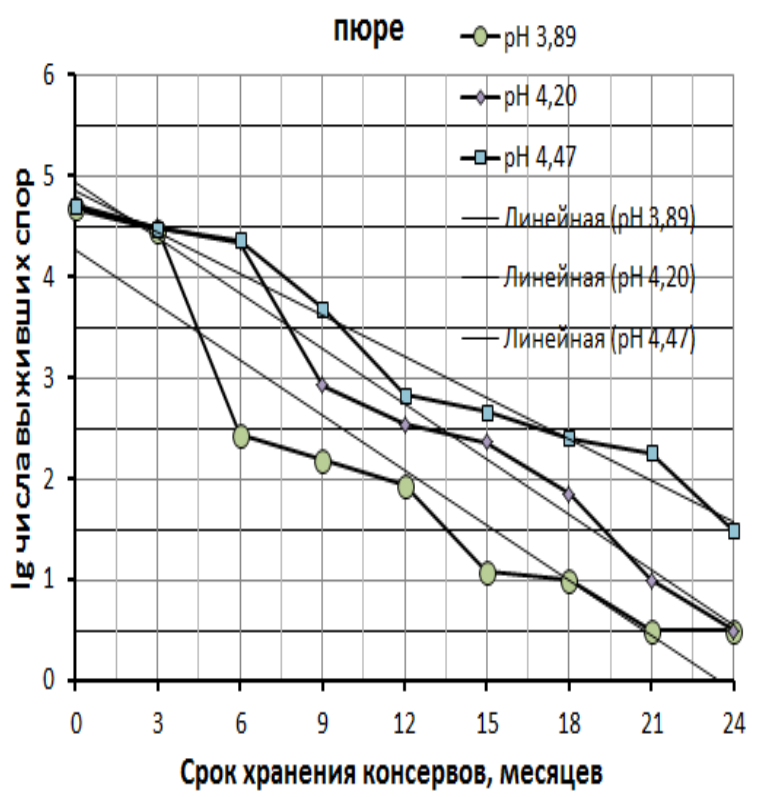

Рисунок 2 - Кинетика гибели спор $C$. botulinum в банановом пюре при различной величине $\mathrm{pH}$ продукта

Экспериментальные данные показали, что в банановом пюре с рН 3,9 после трех месяцев хранения происходило значительное снижение количества жизнеспособных спор C. botulinum. Через 6 месяцев хранения началось более быстрое снижение количества жизнеспособных спор при рН 4,2, чем при 4,47. К концу двухгодичного срока хранения в продукте с рН 3,9 и 4,2 остались жизнеспособными лишь единичные споры в см3 продукта, а в продукте из бананового пюре с рН 4,5 выжили десятки спор в см3 продукта. 


\section{ИЗУЧЕНИЕ КИНЕТИКИ ГИБЕЛИ СПОР CLOSTRIDIUM BOTULINUM ВО ФРУКТОВЫХ КОНСЕРВАХ}

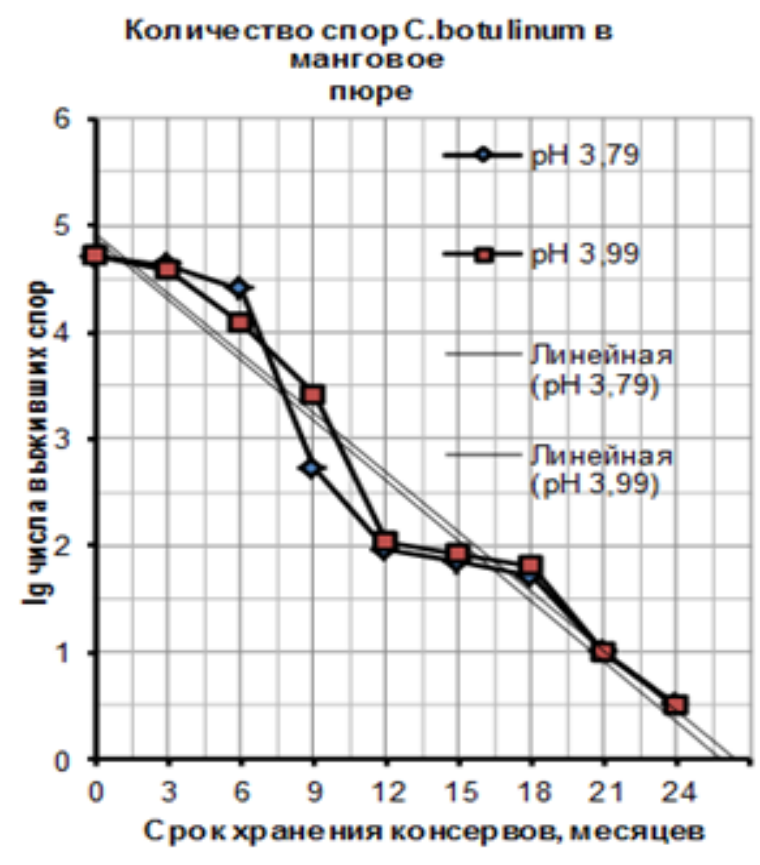

Рисунок 3 - Кинетика гибели спор $C$. botulinum в манговом пюре при различной величине $\mathrm{pH}$ продукта

Скорость гибели спор C. botulinum в манговом пюре в течение первых трех месяцев хранения была небольшой. Гибель спор значительно ускорилась через три месяца хранения продукта с рН 3,8 и через шесть месяцев с pH 3,99. Через 12 месяцев хранения мангового пюре споры отмирали при рН 3,8 и 4,0 с одинаковой скоростью. Через два года хранения в продукте выжили лишь единичные споры в $1 \mathrm{~cm}^{3}$ продукта, как при $\mathrm{pH} 3,8$, так и при $\mathrm{pH} 4,0$.

Экспериментально установлено, что в процессе хранения консервов из манго и бананов происходило отмирание спор C. botulinum с различной скоростью, в зависимости от $\mathrm{pH}$ продукта. Динамика гибели спор в манговом и банановом пюре аналогична скорости гибели спор в абрикосовом пюре при равных значениях рН продукта.

Проведенная работа позволяет поддержать предложенное в статье [6] изменение в Российской Федерации подходов к делению фрруктовых консервов на группы и соответственно, к разработке режимов стерилизации или пастеризации консервов из абрикосов, персиков и груш.

Это изменение будет соответствовать требованиям к аналогичной зарубежной фруктовой продукции, поступающей по импорту. Для этой продукции подобного выделения фрруктовых консервов в группу низкокислотных консервов группы А не существует [13]. Снижение режимов тепловой обработки приведёт к улучшению органолептических показателей консервов из абрикосов, персиков и груш и уменьшению затрат на их производство.

\section{СПИСОК ЛИТЕРАТУРЫ}

1. Технический регламент Таможенного союза ТР ТС 021/2011 «О безопасности пищевой продукции», утвержден 9 декабря 2011 г. № 880.

2. Мазохина-Поршнякова Н.Н. Подавление возбудителей ботулизма в пищевых продуктах. М: Агропромиздат, 1989. $176 \mathrm{c.}$

3. Мазохина-Поршнякова Н.Н., Найдёнова Л.П., Николаева С.А., Розанова Л.И. Анализ и оценка качества консервов по микробиологическим показателям. М.: Пищевая промышленность, 1977. 471c.

4. Червякова К.И., Мордвинова С.А., Коваль Л.Н. Микроб ботулизма в производстве консервов для детей. М.: Консервная и овощесушильная промышленность, 1969. №3. С.30-31.

5. Прохорович Л.Е., Салтыкова Л.А., ШендеровскаяЛ.И. Изучение возможности развития Clostridium botulinum в соке и компоте из абрикосов. М.: Консервная и овощесушильная промышленность, 1976, №1, с.35-38.

6. Волкова Р.А., Позднякова Т.А., Левшенко M.T. Исследование возможности развития спор Clostridium botulinum во фруктовых консервах из персиков, абрикосов и груш. Вестник Крас ГАУ. 2018. № 2. С. 129-136.

7. Положения о разработке режимов стерилизации и пастеризации консервов и консервированных полуфабрикатов, утв. 30 апреля 1983 года. ВНИИКОП.

8. ГОСТ ISO 7218-2015 «Микробиология пищевых продуктов и кормов для животных. Общие требования и рекомендации по микробиологическим исследованиям». М.: Стандартинформ. 2016.

9. Вейшторд И.П., Притыкина Л.А. (ред.) Сборник технологических инструкций по производству консервов, том 2. Консервы для детского и диетического питания. Консервы фруктовые. «Технологическая инструкция по производству фруктовых пюреобразных консервов для детского питания». Фруктовое пюре с сахаром. Пюре из плодов и ягод со сливками «Неженка». М. Пищевая промышленность. 1977 г. С. 43- 55.

10. ГОСТ 10444.1-84 «Консервы. Приготовление растворов реактивов, красок, индикаторов и питательных сред, применяемых в микробиологическом анализе». ИПК Издательство стандартов. 1984

11. ГОСТ 10444.7-86 «Продукты пищевые. Методы выявления ботулинических токсинов и Clostridium botulinum». М.: ИПК Издательство стандартов. 1986.

12. Instruction Manual «HANNA pH 210, $\mathrm{pH} 211$, $\mathrm{pH} 212$, $\mathrm{pH}$ 213. Microprocessor-based Bench $\mathrm{pH} / \mathrm{mV} /$ C Meters». 1978 r. 
13. Кодекс Алиментариус. Кодекс гигиенической практики для низкокислотных и подкисленных консервированных пищевых продуктов. CAC/RCP 23-1979. М.: Издательство «Весь Мир», 1979.

Волкова Раиса Александровна, ведущий научный сотрудник лаборатории качества и безопасности пищевой продукции ВНИИТеК - филиала ФГБНУ «ФНЦ пищевых систем им B.М. Горбатова» РАН. E-mail: microbio@vniitek.ru +7-495-541-76-55
Позднякова Тамара Алексеевна, старший научный сотрудник лаборатории качества и безопасности пищевой продукции ВНИИТеК - фолиала ФГБНУ «ФНЦ пищевых систем им B.М. Горбатова» РАН. E-mail: microbio@vniitek.ru +7-495-541-76-55.

Левшенко Михаил Трифонович, старший научный сотрудник лаборатории качества и безопасности пищевой продукции ВНИИТеК - фрилиала ФГБНУ «ФНЦ пищевых систем им B.M. Горбатова» РАH. E-mail: microbio@vniitek.ru +7-495-541-76-55. 